DOI: 10.12731/2658-6649-2019-11-5-2-12-16

УДК 612.143-612.661

\title{
ОЦЕНКА ПОКАЗАТЕЛЕЙ СЕРДЕЧНО-СОСУДИСТОЙ СИСТЕМЫ У ЛИЦ ЮНОШЕСКОГО ВОЗРАСТА ПРИ ФИЗИЧЕСКОЙ НАГРУЗКЕ
}

\author{
Агеева Е.С., Кадыров Э.Ш., Пантюхова Д.Е., \\ Собкин С.Н., Туманов Ф.А., Хусанов Х.И.
}

В статье представлены данные физического развития лии юношеского возраста. Выявлено, что для юночей характерно пропорииональное телосложение и преобладание мышечной силь по отношению к массе тела, высокий показатель силь, но низкий коэффициент восстановления. Для девушек характерны астенизаиия и коэффициент восстановления после физической нагрузки, соответствуюший состоянию утомления. Выявлена зависимость показателей адаптации к физической нагрузке от типов телосложения. Подавляющее большинство юношей и девушек имели неудовлетворительные показатели адаптации.

Ключевые слова: тип телосложения; коэффициент выносливости; адаптация к физическим нагрузкам.

\section{EVALUTION \\ OF INDICATORS OF THE CARDIOVASCULAR SYSTEM IN ADOLESCENTS UNDER PHYSICAL LOAD}

\author{
Ageeva E.S., Kadyrov E.Sh., Pantyuhova D.E., \\ Sobkin S.N., Tumanov F.A., Husanov H.I.
}

The article presents data on the physical development of youthful persons. It was revealed that a proportional physical and the predominance of muscle strength in relation to body weight, a high strength indicator, but a low recovery coefficient, are characteristic of young men. Girls are characterized by asthenia and recovery coefficient after physical activity, corresponding to a state of fatigue. The dependence of indicators of adaptation to physical activity 
on body types was revealed. The overwhelming majority of boys and girls had unsatisfactory adaptation rates.

Keywords: body type; endurance coefficient; adaptation to physical activity.

\section{Введение}

Тенденция современности - это гиподинамия и увеличение числа людей, имеющих низкий рост и малую или недостаточную массу тела. То есть преобладание юношей и девушек с астеническим телосложением [1, c. 19]. Физическое развитие многостороннее понятие, характеризующее показатели уровня жизни и благополучия населения [2, c. 5]. Степень физического развития определяется совокупностью параметров: развитие мускулатуры, количество мышечной ткани, рельефность, сила, выносливость, ловкость, степенью их выраженности.

Актуальным направлением для научного изучения является определение качества адаптации макроорганизма к физической нагрузке. Для этого требуется исследование особенностей функционирования вегетативной, дыхательной и сердечно-сосудистой систем. Количественный и качественный анализ таких параметров, как частота сердечных сокращений, артериальное давление, сердечный индекс и ударный объем позволяет не только оценить параметры здоровья, но выделить лиц, относящихся к группе риска развития сердечно-сосудистых заболеваний [3, с. 163] .

Умеренная физическая нагрузка приводит к повышению ударного объема сердца, при этом частота сердечных сокращений может не изменяться. При выраженной физической активности повышается симпатический тонус, в результате чего ускоряется частота сердечных сокращений [4, с. 22]. Важно отметить, что увеличение индекса кровообращения и уменьшение периферического сопротивления сосудов взаимосвязаны со снижением крепости телосложения, адаптационным потенциалом и резервными возможностями сердечно-сосудистой системы [5, с. 21].

Целью работы являлся анализ функционального состояния сердечно-сосудистой системы у студентов при физических нагрузках.

\section{Материалы и методы исследования}

Обследовано 248 человек, из них 107 юноши, 141 девушка. Средний возраст составил 18,5+1,6 лет. Исследовали рост, вес и индекс массы тела (ИМТ, у.е.), артериальное давление (АД, мм. рт. ст.) и частоту сердечных сокращений (ЧСС, уд/мин) в ортостатической пробе, ортостатический индекс (ОИ, отн. ед.), коэффициент выносливости (КВ, у. е.), ударный объём крови (УОК, мл/м). 
Для определения адаптации к физическим нагрузкам использовали показатель качества реакции (ПКР), как результат частного между пульсовым давлением и ЧСС до и после нагрузки (функциональной пробы с приседанием). Анализ результатов ПКР проводили исходя из следующего. При ПКР более 1,0 у.е. соответствовало уровню «отлично», при диапазоне $0,5-1,0$ у.е. - «удовлетворительно», при результате менее $0-0,5$ у.е. - «неудовлетворительно». Результаты исследования ПКР соотносили с типами телосложения.

Статистическая обработка данных, полученных в ходе работы, проводилась с помощью пакета программы Statistica 10. Результаты измерений представлены в виде абсолютных и относительных единиц [6, с. 112]. Для проверки нормальности распределения данных использовали критерий Колмагорова-Смирнова. Абсолютные единицы выражены в виде среднего (М) и среднеквадратичного отклонения (m), так как их распределение подчинялось нормальному закону, относительные единицы - в процентах. Для выявления статистической значимости различий показателей в сравниваемых группах использовали критерий Стьюдента. Различия считались достоверными при уровне значимости $\mathrm{p}<0,05$.

\section{Результаты}

При изучении ортостатического индекса было установлено, что у юношей ОИ составил 1,32+0,22 отн.ед., УОК $-75,5+4,3$ мл и ИМТ $-21,9+3,0$ у.е., что соответствовало нормальным показателям. В то время как КВ составил $12,7+1,0$ у.е., что свидетельствовало о состоянии утомления у юношей. Результаты измерений ОИ, УО и ИМТ у девушек не имели статистически значимых различий по сравнению с таковыми у юношей $(1,31+0,24$ отн.ед.; 74,5+5,3 мл и 20,2+3,2 у.е., соответственно). КВ также соответствовал состоянию утомления у девушек.

При анализе показателя качества реакции адаптации к физической нагрузки, исходили из сравнения ПКР с учетом типа телосложения. В результате было установлено, что в исследуемой когорте большая часть студентов относилась к группе мезоморфов (53\%) и эндоморфов $(30 \%)$, в меньшей степени встречались эктоморфы (17\%). Результаты сопоставления продемонстрировали, что показатель качества реакции адаптации к физической нагрузке зависит от типа телосложения. ПКР с уровнем «отлично» имели 7,1\% (2/28) эндоморфов и 5,9\% (1/17) эктоморфов. Удовлетворительный уровень ПКР имели 17,3\% (9/52) мезоморфов, 25,0\% (7/28) среди эндоморфов и $11,8 \%$ (2/17) среди эктоморфов. Неудовлетворительный уровень ПКР был выявлен у 82,7\% (43/52) мезоморфов, 67,9\% (19/28) эндоморфов и $82,3 \%(14 / 17)$ эктоморфов. 


\section{Заключение}

В результате исследования ряда показателей сердечно-сосудистой системы, типа телосложения и адаптации к физической нагрузке, было показано, что для лиц юношеского возраста сохраняется общая тенденция к астенизации и гиподинамии. Исследование данных показателей может служить для своевременного и раннего выявления предвестников риска развития сердечно-сосудистой патологии, роль которых прогрессивно увеличивается с возрастом. Уточнение требуется и для понимания их комбинаций в зависимости от пола и этнических и региональных особенностей.

\section{Список литературы}

1. Артеменков А.А. Проблемы социальной гигиены, здравоохранения и истории // Здравоохранение Российской Федерации. 2012. №3. С. 19-21.

2. Галкина Т.Н. Антропометрические и соматотипологические особенности лиц юношеского возраста в Пензенском регионе: дис. на соискание ученой степени кмн. Волгоград, 2009. 152 с.

3. Манашева Д.И. Показатели физического развития девушек Хакасии / Д.И. Манашева, Е.С. Агеева, А.С. Пуликов // Материалы Седьмой Всероссийской научно-практической конференции. ФГБНУ «Научно-исследовательский институт экспериментальной и клинической медицины». 2015. С. 162-163.

4. Дячук А.В. Анализ показателей кровообращения при наличии предрасположенности к сердечно-сосудистым заболеваниям // Вестник Санкт-Петербургского университета. 2008. Сер. 11 (вып. 1). С. 18-22.

5. Суханова И.В. Соматофизиологические характеристики физического развития юношей Северо-Востока России. Автореферат диссертации на соискание ученой степени кандидата биологических наук. Владивосток, 2007. С. 24.

6. Штыгашева О.В. Подготовка научных работ / О.В. Штыгашева, Е.С. Агеева, О.Ю. Килина. издательство Хакасского государственного университета им. Н. Ф. Катанова. Абакан, 2013. 116 с.

\section{References}

1. Artemenkov A.A. Problemy social'noj gigieny, zdravoohraniyai istorii [Problems of social hygiene, health and history]. Zdravoohranenie Rossijskoj Federacii. 2012. №3, pp. 19-21.

2. Galkina T.N. Antropometricheskie i somatotipologicheskie osobennosti lic yunosheskogo vozrasta $v$ Penzenskom regione [Anthropometric and somatotypological features of youthful persons in the Penza region]. Volgograd, 2009. $152 \mathrm{p}$.

3. Manasheva D.I. Pokazateli fizicheskogo razvitiya devushek Hakasii [Indicators of physical development of girls Khakassia] / D.I. Manasheva, E.S. Ageeva, A.S. 
Pulikov. Materialy Sed'moj Vserossijskoj nauchno-prakticheskoj konferencii. 2015, pp. 162-163.

4. Dyachuk A.V. Analiz pokazatelej krovoobrashcheniya pri nalichii predraspolozhennosti k serdechno-sosudistym zabolevaniyam [Analysis of blood circulation indicators in the presence of predisposition to cardiovascular diseases]. Vestnik Sankt-Peterburgskogo universiteta. 2008. Ser. 11 (issue 1), pp. 18-22.

5. Suhanova I.V. Somatofiziologicheskie harakteristiki fizicheskogo razvitiya yunoshej Severo-Vostoka Rossii [Somatophysiological characteristics of the physical development of young men of the North-East of Russia]. Vladivostok, 2007. P. 24.

6. Shtygasheva O.V. Podgotovka nauchnyh rabot [Preparation of scientific papers] / O.V. Shtygasheva, E.S. Ageeva, O.Yu. Kilina. Abakan, 2013. 116 p.

\section{ДАННЫЕ ОБ АВТОРАХ}

Агеева Елизавета Сергеевна, доктор медицинских наук, доцент, заведующий кафедрой биологии медицинской

Медицинская академия имени С.И. Георгиевского ФГАОУ ВО «КФУ им. В.И. Вернадского»

бульвар Ленина, 5/7, г. Симферополь, Республика Крым, 295051, Российская Федерачия ageevaeliz@rambler.ru

Кадыров Э.Ш., Пантюхова Д.Е., Собкин С.Н., Туманов Ф.А., Хусанов Х.И. Медииинская академия имени С.И. Георгиевского ФГАОУ ВО «КФУ им. В.И. Вернадского»

бульвар Ленина, 5/7, г. Симферополь, Республика Крым, 295051, Российская Федерация

\section{DATA ABOUT THE AUTHORS}

Ageeva Elizaveta Sergeevna, Doctor of Medicine, Associate Professor, Head of the Department of Medical Biology

Medical Academy named after S.I. Georgievsky of Vernadsky CFU

5/7, Lenin Ave., Simferopol, Republic of Crimea, 295051, Russian Federation

ageevaeliz@rambler.ru

Kadyrov E.Sh., Pantyukhova D.E., Sobkin S.N., Tumanov F.A., Husanov H.I. Medical Academy named after S.I. Georgievsky of Vernadsky CFU 5/7, Lenin Ave., Simferopol, Republic of Crimea, 295051, Russian Federation 